\title{
COMPUTERS AS A LANGUAGE LEARNING TOOL
}

\author{
Bernd Ruschoff
}

\begin{abstract}
The subject of CALL has only recently been introduced to language teachers in West Germany. While in other European countries many institutions are involved in projects dealing with the use of computers in language learning. The Audio-Visual Media Centre (AVMZ), Bergische Universitat-CH Wuppertal, 5600 Wuppertal 1, is one of the few places in this country investigating various approaches to CALL.

This article describes the general concept of the project and the kind of programs being developed and used. Furthermore, it is intended to solicit comments from scholars and institutions in the USA and thus established contacts and initiate an exchange of ideas.

KEY WORDS: Computer, German, language laboratories, learning laboratories.
\end{abstract}

The use of computer technology as a learning tool is becoming increasingly important in education. While teachers in West Germany are gradually accepting the use of computers as part of the curriculae of science subjects, computer-assisted language learning (CALL) with all its potential applications and advantages as well as possible limitations is still widely neglected in this country.

The Audio-Visual Media Centre (AVMZ) at the University of Wuppertal is one of the few places in West Cermany which is currently conducting research into CALL. We feel that it is important to look into this subject now, because we might still be able to influence future developments and thus avoid some of the mistakes that have been made in the past when new technical aids were introduced. With regard to this problem Graham Davies quite rightly points out that "the language laboratory does not have a good track record and many teachers are sceptical about new electronic gadgets...". (1)

In our opinion the poor track record of some of the AV media is due to two reasons. First of all, new technical aids were in many cases never properly introduced to teachers. They were often never taught how to make the most of $A V$ aids and how to integrate these into their teaching units. Consequently, results achieved did not match the high expectations raised by commercial producers of software and hardware. Secondly, programs and teaching materials were to

Dr. Bernd Ruschoff specialized in the use of technical media in language teaching. As Head of the language section of the Audio-Visual Media Centre (AVMZ) at the University of Wuppertal he is at the moment conducting research into computer assisted ranguage learning (CALL). Nachrichtentechnik. (Berlin: 1983) 
begin with far less sophisticated than the hardware. A critical analysis of both its benefits and its limitations began much too late.

Bearing in mind the points raised above, our project attempts to "kill two birds with one stone" (if you will permit the use of the idiom). Of course, one aspect is that we are offering teachers the opportunity to familiarize themselves with the various roles computers can play in language learning. We are trying to demonstrate to them that computers are not just 'electronic gadgets', but may well enhance the effectiveness of their language teaching curriculae, if properly used.

Much to our surprise, initial reactions to our programs as well as the very idea of using computers in language learning have in general been positive. However, the really important aspect of our project is that we are constantly trying to allow the reactions, comments and suggestions on our programs by the teachers to influence our software developments. We feel that in this way our CALL materials can best be tailored according to the actual needs of both teachers and students.

Although we are still at the beginning of our investigations, a few points have become evident from our discussions with teachers at regional schools and lectures at our university as well as from first trials of our programs with students. Users are quite impressed with the ways in which the technique of branching allows the use of the computer as an interactive learning partner for the student. Therefore, one of the aims of our project is to set up a typology of exercises and drills which can make best use of the fact that the computer can provide the student with proper feedback on his learning effort at a time when it is most beneficial to him, i.e., at the very moment when he is concentrating on solving a given problem.

It is felt that simply translating traditional paper-based exercises into computer programs is not enough. As readers familiar with CALL know, the creative use of branching not only permits us to devise programs which immediately respond to the student's input, but also guide him towards the correct solution by means of reinforcement comments or helpful hints should he make a mistake at first. Research is needed to establish the most effective kinds of helpful comments. This may well lead to new types of language learning exercises.

Apart from the types of programs suggested by John Higgins and Tim Johns (2), vocabulary building exercises and grammatical drills in which these comments or prompts are formulated on the basis of a detailed analysis of most frequent learner errors will greatly enhance the effectiveness of self-study materials. Furthermore, programs which simultaneously perform a comprehensive analysis of a learner's mistake(s) could become standard CALL material. Spelling tests such as the ones suggested by Marmo Soenarmo (3), are a step in the right direction. 
The introduction of an audio component to CALL by using computer controlled cassette recorders may well lead to a revival of language lab materials. Listening comprehension and pronunciation exercises, thus far the domain of the traditional language lab, can also benefit from the fact that AV hardware combined with a microcomputer can actually lead to interactive dialogues between the learner and the technical aid. We are working on software for such hardware configurations and are now in the first stages of setting up a fully interactive AV learning lab.

Another aspect of CALL is the fact that teachers want to have an option to change the content of a given program structure according to the specific needs of their own curriculum. John Higgins states that teachers working with CALL materials "...may wish to find out enough about the underlying technology in order to modify programs, to tailor them to local needs..." (4). However, our experience from lecturing on the use of technical media indicates that most teachers want (and need) fool-proof, easy-to-use media materials, while only a minority have the time and are interested to find out about the technical background of a given technical aid.

Consequently, all our programs are designed as authoring systems. As stated above, we intend to set up a typology of computer-based language learning materials. In doing so we want to develop a set of CALL exercises which allow the teacher to change the content by means of a kind of word processing system. All the instructions needed to implement such changes appear on the screen, and the teacher simply uses the computer keyboard as a typewriter.

Finally, CALL materials should have an element of progression together with an element which explicitly links the computer-based exercise with the rest of the teaching unit's activities. By progression we mean that the program should have various stages which are built on each other and further develop the language point practiced in the preceding stage. Thus a simple drill becomes a real exercise which takes the student from simply learning a word or a structure to using it creatively as part of one program.

To give but one example of this concept, we have developed a multiple-choice translation exercise intended to practice terminology related to a certain subject area. In the first stage a German word appears on the screen and the student is offered three English words and asked to type in the translation of his choice. The choice offered to the student should be based on an analysis of most common translation errors of the particular term. The following example is taken from a version of the program used by German students of English literature: 
This is the term you have to translate:

ROMANLITERATUR

Please choose from the following options:
(A) PROSE
(B) FICTION
(C) NOVEL LITERATURE

Your answer:

Once the student has entered the correct solution, the second stage involves translating a sentence with the word in it (5). In this stage, the sentence is presented on the screen and the student has to write his translation on a worksheet. At the end of the exercise he hands in the worksheet for correction by the teacher.

This follow-up task as an explicit part of the CALL program provides the learner with a link between the computer-based part of the teaching unit and the teacher as well as the rest of the unit's activities. It also enables the teacher to check on the progress made by the learner when using the program. Furthermore, the follow-up task leads to a second level of feedback to reinforce the effectiveness of the CALL program, which can only be provided by the teacher. It also ensures that this feedback closely relates to the way in which the learner has worked with the program. Thus both teacher and student can appreciate that the computer is not just a fancy electronic gadget but a valuable tool for teaching and learning (6).

Structuring a CALL program in the way exemplified above is in our opinion one way of ensuring a certain element of progression in computer-based self-study materials. The program prepares the student for the actual aim of the unit, i.e., to be able to translate complete texts on a certain subject, not just by learning or practicing the terminology needed for the translation, but by including a short translation task as the second stage of the exercise. In this way the student has to immediately use the word just learned creatively. The obvious advantage of such an interactive program over paper-based drills for vocabulary building further stresses the importance of developing truly original CALL materials. 
1. Graham Davies, Computers, Language and Language Learning. (London: 1982), p. vii.

2. cf. John Higgins \& Tim Johns, Computers in Language Learning. (London: 1983).

3. cf. Marmo Soenarmo, "Programming for Misspelled Extended Input", CALICO Journal, Vol. 1, No. 3 (1983), pp. 31ff.

4. John Higgins \& Tim Johns, op. cit., p. 100.

5. The question and answer routine makes use of branching. Every word translated incorrectly at first is repeated after five terms have been dealt with. The program may, of course, be adapted for use with other languages.

6. For further examples of CALL materials developed along these lines see: Bernd Ruschoff, "The Integration of CALL Materials into the Overall Curriculum", CALICO Journal, Vol. 1, No. 4 (1984), pp. $26 \mathrm{ff}$.

International Association for Learning Laboratories

NALLD JOURNAL

New Advances in Learning Laboratory Development

Name

Title

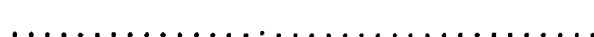

Institution

Address to which NALLD JOURNAL is to be sent:

Address

City ............ State ..... Zip

\section{MEMBERSHIP}

New Member

North American

U.S./Can/Mexico

All libraries +

Foreign air mall

Student

Sustaining

Member

Return this form to:

NALLD JOURNAL

Academic Publications

Administration Building

University of Louisville, KY

40292 
$\stackrel{w}{\omega}$

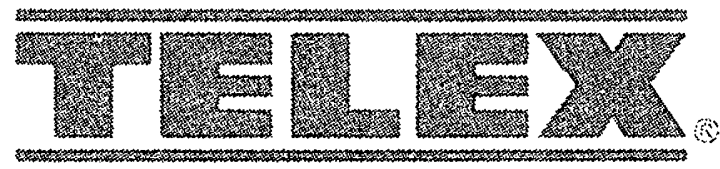

2
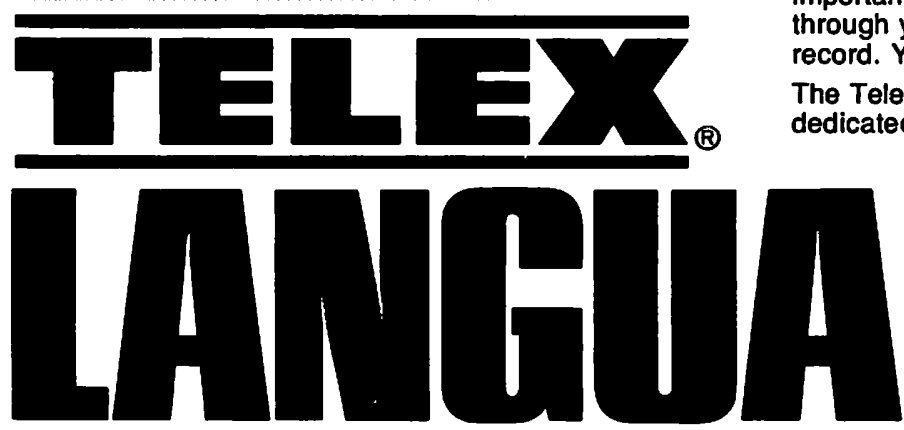

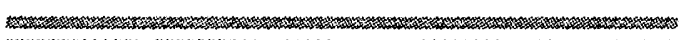

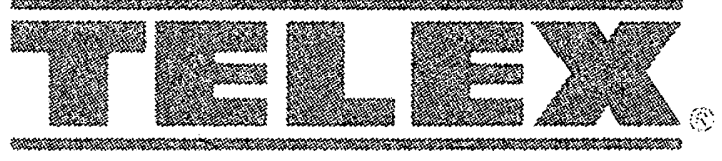

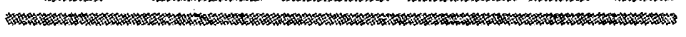

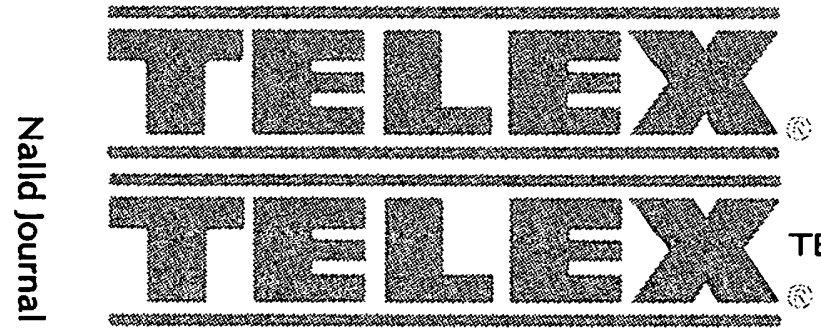

\section{THE DEDICATED LANGUAGE} LAB... A LONG LASTING CHOICE.

When selecting equipment for permanent language lab installations it is important to choose a manufacturer who has earned a strong reputation through years of quality educational products and a reliable service record. You need a company who will back you up now AND in the future.

The Telex Audio Classroom 200 was designed specifically for the dedicated classroom and is capable of all levels of language teaching.
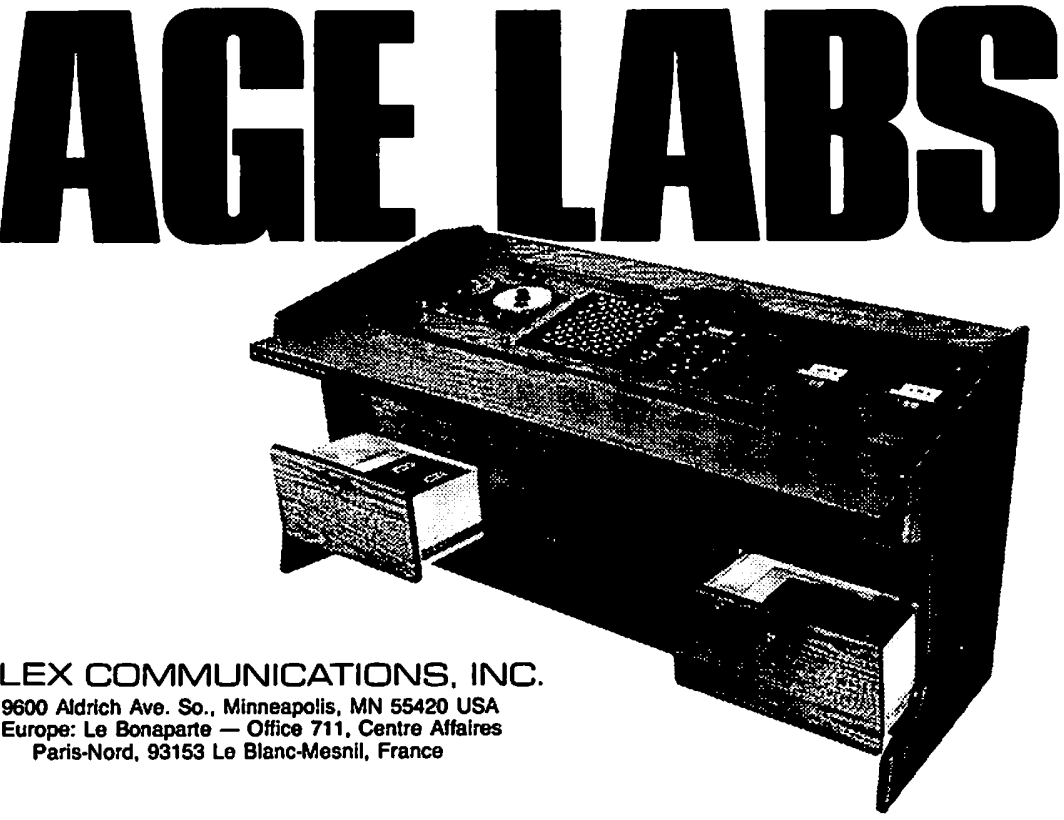